\title{
Anti-Corruption Policies in Mongolia
}

\author{
Urangoo Khash-Erdene (First author) \\ Department of Security Management, Kyonggi University, Republic of Korea
}

Dr. Julak Lee (Corresponding author)

Associate Professor, Department of Security Management, Kyonggi University, Republic of Korea.

Received: April 22, 2018 Accepted: June 8, 2018 Online published: June 11, 2018

doi:10.5296/jpag.v8i2.13120 URL: https://doi.org/10.5296/jpag.v8i2.13120

\begin{abstract}
Since the 1990s, when Mongolia has transited to democracy and market economy, which began to reform all parts of society, corruption has become a serious issue. Though corruption does not trigger a fear like violent crimes, it is a very dangerous phenomenon that spreads all sectors of society in a hidden way, and there is no particular victim of corruption, but the society.
\end{abstract}

Nowadays, the main obstacle to socio-economic growth in developing countries is corruption. Therefore, it is essential to know the nature, causes, characteristics, and structures of corruption in order to develop and implement an effective anti-corruption program.

There is a need to fight against political and high-level corruption in Mongolia, as a country developing nation's economy based on the mining sector. This article looks at the corruption situation in Mongolia, its factors, causes and methods, the results of surveys on anti-corruption activities in Mongolia, and the nation's experience in fighting corruption.

The article compares, summarizes and analyses studies the reports conducted by the Independent Authority Against Corruption of Mongolia, a nationwide survey on Perceptions and Knowledge of Corruption in Mongolia 2017, and other works of research institutions, and analysts.

Corruption as a pressing issue of Mongolian society remains a cause for concern at both the administrative and elite levels paralyzing Mongolian decision making. The enforcement of anti-corruption policies is itself marred by corrupt practices and threats of mutual exposure.

There is an increasing need to educate the public and to propagate the view of zero-tolerance 
for corruption and bribery throughout the society. Also it is essential to increase transparency in political activities, and the willingness of politicians in fighting against corruption.

Keywords: Mongolia, corruption, anti-corruption policies, independent authority against corruption, political corruption.

\section{Introduction}

Having a variety of definitions, the corruption has been widely studied and published by international organizations and non-government organizations. The word 'corruption' is defined in the first as greediness, and profit by unlawful or improper means, and secondly, the bribery in the Mongolian concise dictionary by Tsevel (1966: 16). This word 'corruption' is derived from a Latin word 'corruption', mostly dishonesty, improper and illegal behavior by people in power or authority as defined in an English dictionary (Summers, 1995: 306). In summary of these definitions by experts, the corruption means improper behavior that satisfy own interest by selling public interests.

Mongolia had a work strategy on combating corruption, having developed a national program on Combating Corruption in November of 2016 approved by the parliament, and the action plan of this national program approved in April of 2017.

Despite some positive outcomes and comparative changes in the general indicators on corruption as considered by international organizations in recent years, Mongolia is aimed at reforming activities of the Independent Authority against Corruption and bringing the actions on fighting corruption to the next level of other developed countries based on public support and information. As a nation, where the industry of mining and mineral resources has been developing, we are required that we lower the index of corruption to attract foreign investments due to the high risk of corruption.

\section{Legal Basis of Anti-Corruption Actions}

Over the last 20 years driven by globalization, the international relations have encountered favorable conditions and opportunities, as well as new era of prosperity, not seen before, while it is followed by globalized adverse effects.

The corruption is duly counted as one of those effects. No country could combat this negative phenomenon in societies alone to bring efficiency. In this regard, the United Nations adopted the Convention against Corruption in 2003, taking this situation into consideration, to cooperate at international level. The Convention against Corruption mentions in its preamble about the seriousness of problems and threats posed by corruption to the stability and security of societies, undermining the institutions and values of democracy, ethical values and justice and jeopardizing sustainable development and the rule of law. ${ }^{1}$

The ratification of the UN Convention against Corruption by the parliament of Mongolia in 2005 extensively presented the will of combating corruption. Mongolian parliament revised

\footnotetext{
${ }^{1}$ http://www.legalinfo.mn/annex/details/6492?lawid=10269
} 
the law on Anti-Corruption on July 6 of 2006 which entered into force on November 1 of 2006. The atmosphere, where all society recognized that the process of actions on anti-corruption was slow and ineffective, became the cause of revising the law on Anti-corruption.

As stipulated in the national program on Combating Corruption approved by the parliamentary resolution on November 3 of 2016, the Independent Authority against Corruption /IAAC/ which is the special agency established for fighting corruption for the first time in Mongolia under the law on Anti-corruption and started to operate on January 1 of 2007.

The Independent Authority against Corruption is engaged in organizing, monitoring and analyzing the implementation of this program; assessment, suggestion and recommendation; development of the methodology; coordination of activities of implementing agencies; facilitation of cooperation and regional and international organizations; and providing the public with information on the program implementation.

\section{Overall Nature of Corruption in Mongolia}

The IAAC has conducted 3 surveys to determine the overall nature of corruption in Mongolia, while other international surveys displayed the same situation (IAAC, 2017: 21-27).

\subsection{Integrity Assessment}

Functions of the IAAC includes 'to conduct studies on the forms, extent and causes of corruption no less than once in two years and issue the corruption index report and publish the results' in compliance with the article 18.1.3 of Anti-corruption law, and 'to assess the level of integrity at government organizations and inform the public, based upon a survey conducted among individuals and legal entities provided public services" under the Article 18.1.7 of the law.

Under this function, the integrity assessment involves around 500 citizens and organizations, and public officials and experts who provide civil services.

The integrity assessment (IA) consists of assessments of internal and external integrity and policy participants as follows:

- External integrity assessment is made by citizens and entities provided by public services

- Internal integrity assessment is an assessment made by public servants on their organizations

- Policy participants' assessment is made by participants, experts and researchers who are involved in policy making and planning of the activities of their organizations

The assessment is scored by 1-100, and score 100 is the most positive value. 2016 assessment involved 60 public organizations (ministry, government agency, governor of Aimag and capital city), and the overall score was 69.7 which is 4.2 score lower than that of previous 
year.

Table 1. IA of government organization, by sub-indicator

\begin{tabular}{l|c|c|}
\hline \multicolumn{1}{|c|}{ Indicator } & $\mathbf{2 0 1 5}$ & $\mathbf{2 0 1 6}$ \\
\hline IA & $\mathbf{7 3 . 8}$ & $\mathbf{6 9 . 7}$ \\
\hline 1. External IA & 69.8 & 63.3 \\
\hline - Transparency and accountability index & 61.2 & 57.5 \\
\hline - Corruption index & 78.5 & 69.1 \\
\hline 2. Internal IA & 81.9 & 80.9 \\
\hline - Cultural index & 74.4 & 72.1 \\
\hline - Workplace integrity index & 89.4 & 89.6 \\
\hline 3. Policy participants assessment & 69.8 & 64.8 \\
\hline
\end{tabular}

The assessment of citizens and entities that received public service was declined by 6.5 score, experts' assessment by 5.0 score, and civil servants by 1.0 score respectively, all of which influenced the decline of overall rate.

Table 2. Integrity assessment-2016, by organization

\begin{tabular}{l|l|c}
\hline Order & Organization- ministry & Score \\
\hline $\mathbf{1 3}$ & Ministry of education, culture, science and sports & $\mathbf{6 4 . 0}$ \\
\hline $\mathbf{1 2}$ & Ministry of road and transportation development & $\mathbf{6 4 . 5}$ \\
\hline $\mathbf{1 1}$ & Ministry of mining and heavy industry & $\mathbf{6 5 . 3}$ \\
\hline $\mathbf{1 0}$ & Ministry of environment and tourism & $\mathbf{6 5 . 5}$ \\
\hline $\mathbf{9}$ & Ministry of construction and urban development & $\mathbf{6 5 . 7}$ \\
\hline $\mathbf{8}$ & Ministry of justice and internal affairs & $\mathbf{6 6 . 6}$ \\
\hline $\mathbf{7}$ & Ministry of health & $\mathbf{6 6 . 7}$ \\
\hline $\mathbf{6}$ & Ministry of energy & $\mathbf{6 9 . 0}$ \\
\hline $\mathbf{5}$ & Ministry of labor and social welfare & $\mathbf{7 1 . 9}$ \\
\hline $\mathbf{4}$ & Ministry of food, agriculture and light industry & $\mathbf{7 3 . 3}$ \\
\hline $\mathbf{3}$ & Ministry of foreign affairs & $\mathbf{7 3 . 5}$ \\
\hline $\mathbf{2}$ & Ministry of finance & $\mathbf{7 5 . 5}$ \\
\hline $\mathbf{1}$ & Ministry of defense & $\mathbf{7 7 . 7}$ \\
\hline
\end{tabular}

\begin{tabular}{l|l|c}
\hline Order & Organization- agency & Point \\
\hline $\mathbf{2 5}$ & Physical culture and sports authority & $\mathbf{6 1 . 4}$ \\
\hline $\mathbf{2 4}$ & General police department & $\mathbf{6 2 . 0}$ \\
\hline $\mathbf{2 3}$ & Department of arts and culture & $\mathbf{6 2 . 9}$ \\
\hline $\mathbf{2 2}$ & General staff of armed forces & $\mathbf{6 3 . 2}$ \\
\hline $\mathbf{2 1}$ & Minerals and petroleum authority & $\mathbf{6 4 . 9}$ \\
\hline $\mathbf{2 0}$ & Customs agency & $\mathbf{6 5 . 9}$ \\
\hline $\mathbf{1 9}$ & Administration of land affairs, geodesy, and cartography & $\mathbf{6 7 . 0}$ \\
\hline $\mathbf{1 8}$ & Authority for fair competition and consumer protection & $\mathbf{6 9 . 6}$ \\
\hline $\mathbf{1 7}$ & Veterinary and animal breeding agency & $\mathbf{6 9 . 9}$ \\
\hline
\end{tabular}




\begin{tabular}{l|l|c}
$\mathbf{1 6}$ & State professional inspection agency & $\mathbf{7 0 . 5}$ \\
\hline $\mathbf{1 5}$ & General department of taxation & $\mathbf{7 0 . 7}$ \\
\hline $\mathbf{1 4}$ & Agency for policy coordination on state property & $\mathbf{7 1 . 2}$ \\
\hline $\mathbf{1 3}$ & General executive agency of court decision & $\mathbf{7 1 . 4}$ \\
\hline $\mathbf{1 2}$ & Civil aviation authority & $\mathbf{7 1 . 5}$ \\
\hline $\mathbf{1 1}$ & General agency for labor and social services & $\mathbf{7 2 . 1}$ \\
\hline $\mathbf{1 0}$ & General authority for health and social insurance & $\mathbf{7 2 . 4}$ \\
\hline $\mathbf{9}$ & National emergency management agency & $\mathbf{7 3 . 4}$ \\
\hline $\mathbf{8}$ & General authority for state registration and intellectual property & $\mathbf{7 3 . 5}$ \\
\hline $\mathbf{7}$ & General agency for meteorology and environment monitoring & $\mathbf{7 3 . 8}$ \\
\hline $\mathbf{6}$ & Family, youth and child development agency & $\mathbf{7 3 . 8}$ \\
\hline $\mathbf{5}$ & Agency for standardization and metrology & $\mathbf{7 4 . 1}$ \\
\hline $\mathbf{4}$ & Communications and information technology authority & $\mathbf{7 4 . 1}$ \\
\hline $\mathbf{3}$ & Immigration agency & $\mathbf{7 4 . 1}$ \\
\hline $\mathbf{2}$ & National development agency & $\mathbf{7 5 . 2}$ \\
\hline $\mathbf{1}$ & General archival authority & $\mathbf{7 7 . 3}$ \\
\hline
\end{tabular}

When asked the question 'Which institution of Mongolia is the most corrupt?' from the respondents of IA survey, $46.4 \%$ said land office, $44.7 \%$ health organization, $38.6 \%$ court, $37.7 \%$ customs office, $33.0 \%$ state administrative body, ministry, and agency, and $32.2 \%$ specialized inspection agency.

Table 3. Most corrupt institutions in Mongolia (by percentage per score)

\begin{tabular}{l|c|c}
\hline \multicolumn{1}{c|}{ Institution } & 2015 & 2016 \\
\hline Land service organization & 40.0 & 46.4 \\
\hline Health care organization & 46.9 & 44.7 \\
\hline Court & 36.8 & 38.6 \\
\hline Customs office & 36.8 & 37.7 \\
\hline State administrative body, ministry and agency & 27.2 & 33.0 \\
\hline Professional inspection agency & 31.5 & 32.2 \\
\hline Political party & 19.8 & 31.5 \\
\hline Police department & 31.4 & 30.9 \\
\hline Educational organization & 24.7 & 30.5 \\
\hline Tax office & 24.0 & 24.0 \\
\hline Prosecutor's office & 17.1 & 22.3 \\
\hline Local administrative body & 16.4 & 18.1 \\
\hline Media organization & 9.4 & 12.0 \\
\hline Private sector & 4.8 & 7.0 \\
\hline Non-government organization & 3.9 & 6.5 \\
\hline Other & 3.0 & 5.4 \\
\hline
\end{tabular}

Government organizations are required to pay attention to increase transparency and accountability, publicize their activities on fighting against corruption, and ensure integrity and transparency of human resources policy and to encourage and stimulate the will of their management in the fight for corruption. 
3.2 Corruption Perception Survey of Political and Law Enforcement Institutions

The Independent authority against corruption has conducted 9 times the 'Corruption perception survey on political and law enforcement institutions'. The rate of political corruption was 3.65 in 2016 as the same as the result of previous year, indicating the political corruption is widely spread throughout Mongolia.

Funding mechanism of election and political parties, and the conflict of interest of business groups in political arena were the main causes of political corruption. Additionally, absence of liabilities of officials, who breached the laws and regulations, and delayering, overlap and gap, and poor monitoring on implementation of laws are the factors of forming political corruption.

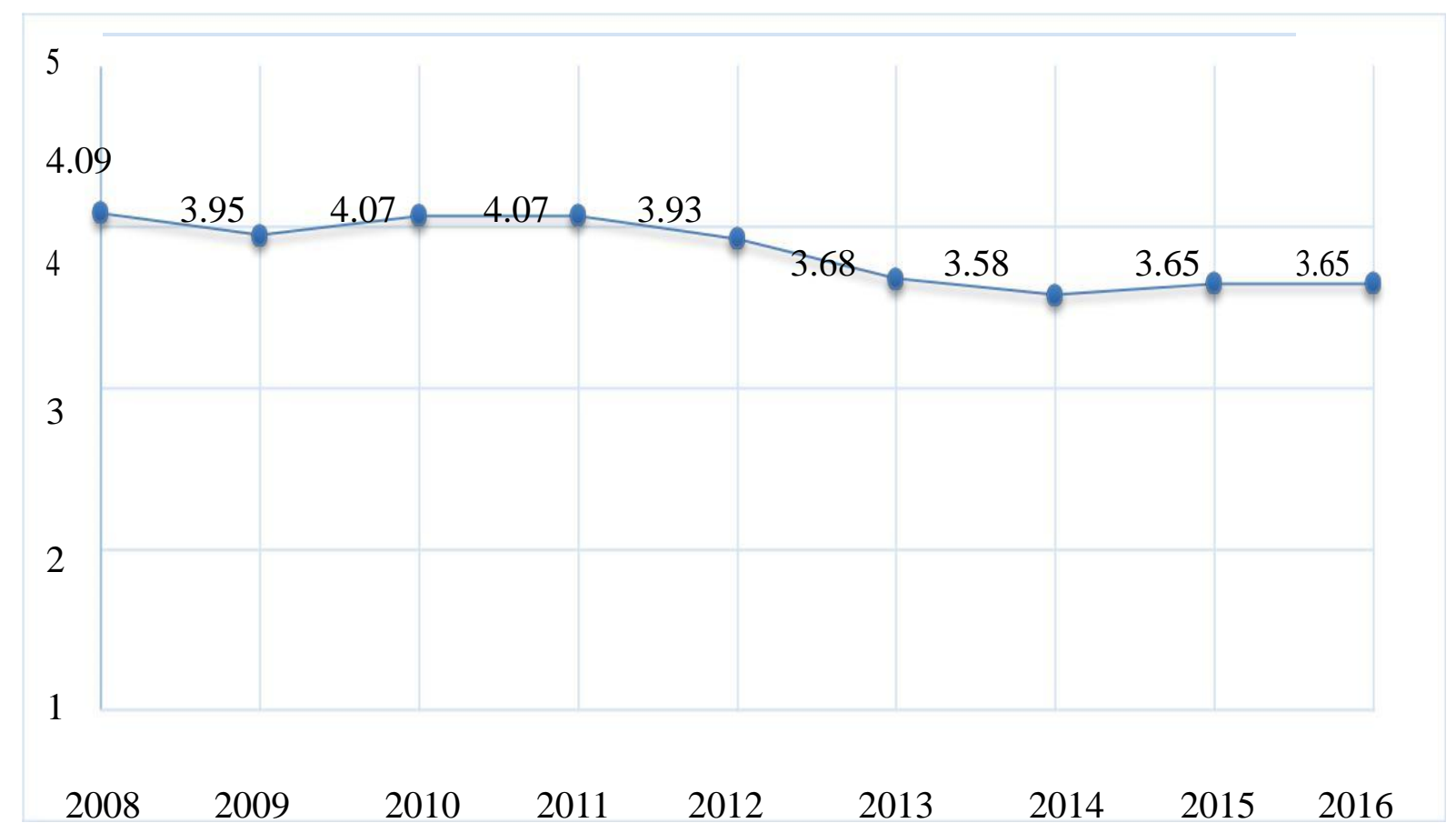

Figure 1. Political corruption rate 2008-2016

Four indicators are used to determine the rate of political corruption. 2016 survey indicated the scope of political corruption decreased by $0.10 \%$ as compared to the previous year, and the form remained the same. The causes of corruption increased by 0.09 point, while the loss and result increased by 0.05 point (The index values are measured by 1 to 5 , and value close to 1 represents incorruptness).

In conclusion of the survey data, the decrease of political corruption scope shows positive result, whereas the increase of causes and loss bring negative result to the corruption assessment. I consider that further detailed analysis of causes and loss, and identification of causes led to such losses would be a factor to reduce the political corruption rate.

The losses caused in the scope of political corruption have created many negative economic 
and social phenomena throughout the country, including deterioration of economic power and investment, increase of inequality of properties, and breach of justice in the society.

Experts emphasized that illegal actions and fights for power in the course of regular parliamentary election of Mongolia became main factors of political corruption.

\subsection{Corruption Perception Index}

Transparency International compares and evaluates how the corruption rate of world countries are changing, and started to evaluate the Corruption perception index (CPI) with 0 (corrupted)-100 (uncorrupted) scores in 2012 (The index has been scored by 0-100 score since 2012 and close to 100 score illustrates incorruptness, while close to 0 score shows corruptness). In CPI survey 2016, our country took 38 scores, rating at 87 th place among 176 countries.

In comparison of this survey with that of 2015 , the CPI declined by 1 point that resulted in shifting 15 positions down. In 2016, Mongolia, evaluated by 8 indicators, was assessed by 9 indicators (34 scores for additional indicator 'Varieties of Democracy Project') which influenced on the decrease of total score Besides, the number of respondent countries increased by 8 which might become one of the causes led to this drop.

Table 4. Index value of corruption perception index and ranks among countries involved in the evaluation

\begin{tabular}{l|c|c|c|c|c}
\hline & $\mathbf{2 0 1 2}^{\mathbf{4}}$ & $\mathbf{2 0 1 3}$ & $\mathbf{2 0 1 4}$ & $\mathbf{2 0 1 5}$ & $\mathbf{2 0 1 6}$ \\
\hline Corruption perception index value & 36 & 38 & 39 & 39 & 38 \\
\hline Rank of Mongolia & 94 & 83 & 80 & 72 & 87 \\
\hline Number of respondent countries & 176 & 177 & 175 & 168 & 176 \\
\hline
\end{tabular}

The estimation of CPI which uses 13 information sources used 9 sources for the index assessment of Mongolia. For the other indicators used for previous assessment, the increase was shown in 'Political risk services'- Risk rating by 1 , World justice project- Rule of law index by 3 , 'Global insight' - Country risk ratings by 4 , whereas decrease was displayed in World Economic Forum- Executive opinion survey by 4, IMD- World competitiveness rankings by 2 and Economic intelligence unit- Country risk rating by 1 respectively.

The report says 'The result of this year's survey specifically stresses out the correlation between corruption and injustice, of which mutual impact creates corruption, power and wealth inequality, in addition to populism, in the society. Populist politicians, who give an oath to cut the connection of corruption and power, are publicly promoted.' 


\section{Macrothink}

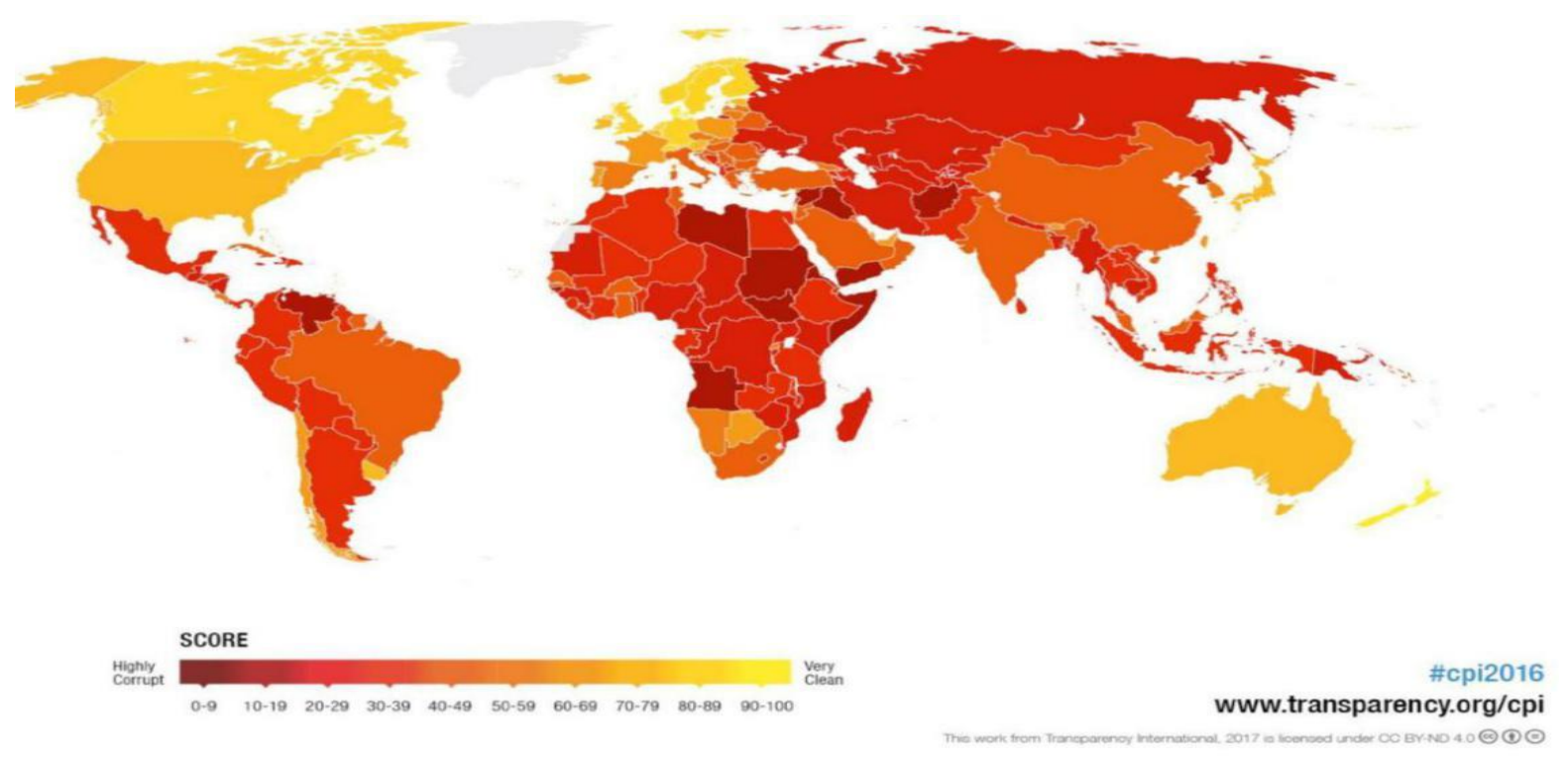

Figure 2. Corruption perception index, $2016^{2}$

According to the Corruption perception index, the Russian Federation was ranked at 131 with 29 scores (no change in scores, but shifted 15 positions down as compared to previous years), while the People's Republic of China was ranked 79 with 40 scores (increase in scores by 3, and the rank by 4 as compared to previous years). In CPI 2016, New Zealand, Denmark, Finland, Sweden, Switzerland, Norway, Singapore, Netherlands, Canada and Germany had higher scores, while Somalia, South Sudan, North Korea, Syria, Sudan, Yemen, Libya, Afghanistan, Guinea, Iraq, Venezuela, Eritrea and Angola had the lowest scores.

\subsection{Global Corruption Barometer}

In the scope of Global Corruption Barometer, a series of regional study, Transparent International has surveyed around 22000 people in 16 Asia- Pacific countries on their view of corruption. According to the result of the survey, a fourth of respondents have given a bribe to have public service. The police offices lead the list of state service providers that are taking bribes. Nearly a third of survey respondents have offered a bribe to police officials for the last 12 months.

$20 \%$ of the respondents answered that they have given a bribe to be provided by the state service, while $61 \%$ said 'poorly', when they were asked 'How the government is working to fight against the corruption in Mongolia?' $16 \%$ offered a bribe to hospitals, whereas $16 \%$ gave a bribe to police officials. ${ }^{3}$

Based on the result of this survey, Transparency International has given 4 basic recommendations to countries of the Asia-Pacific region:

\footnotetext{
${ }^{2}$ http://www.transparency.org/news/feature/corruption_perceptions_index_2016\#resource

3 http://www.transparency.org/whatwedo/publication/people and corruption asia pacific global corruption barometer
} 
1. Integrate actions on combating corruption with all objectives of the Sustainable Development Goals, including poverty, hunger, education, health, gender and climate change, and develop a mechanism for reducing corruption risk;

2. Based on current international standards developed by organizations such as Transparency International, create complex legal environment to protect whistleblowers;

3. For the purpose of ending the impunity pursuant to bribery, impose liabilities to briber and bribe and take measures on preventing from bribery

4. Cooperate and support citizens who rejected to take bribes and informed of corruption.

\subsection{Rule of Law Index}

'World Justice Project' is an independent and non-profit organization which evaluates adherence of countries to the rule of law based on surveys. 2016 survey on rule of law covered 113 countries, including Mongolia which ranked 55 with 0.54 scores advancing its rank by 1 position as compared to the previous year.

Table 5. Rule of Law Index by sub-indicator, Mongolia

\begin{tabular}{l|c|c|c}
\hline Indicator & 2014 & 2015 & 2016 \\
\hline Rule of law index & $\mathbf{0 . 5 1}$ & $\mathbf{0 . 5 3}$ & $\mathbf{0 . 5 4}$ \\
\hline - absence of corruption & 0.39 & 0.42 & 0.41 \\
\hline -order and security & 0.78 & 0.79 & 0.79 \\
\hline -fundamental rights and freedom & 0.61 & 0.61 & 0.60 \\
\hline -constraints on government powers & 0.53 & 0.54 & 0.53 \\
\hline -civil justice & 0.52 & 0.55 & 0.54 \\
\hline - -regulatinal justice & 0.48 & 0.42 & 0.48 \\
\hline -open governforcement & 0.43 & 0.48 & 0.47 \\
\hline
\end{tabular}

Looking at the sub-indicator of absence of corruption of Mongolia, the rate of regulatory enforcement (0.14) and executive governance (0.42) is comparatively low.

According to the Rule of law index 2014, Denmark (0.89), Norway (0.88), Finland (0.87), Sweden (0.86), Netherlands (0.86) ranked the highest, but Venezuela (0.28), Cambodia (0.33), Afghanistan (0.35), and Egypt (0.37) ranked the lowest. Mongolia received 0.54 scores as the same as Bulgaria, Macedonia, Malaysia and Belorussia.

\subsection{Problems Facing Mongolia}

In June 2017, The Asia Foundation, in collaboration with Sant-Maral Foundation, conducted its eighteenth Survey on Perceptions and Knowledge of Corruption (SPEAK) in Mongolia, a nationwide survey of citizens in rural Soums, Aimags, and the capital city Ulaanbaatar. This survey is conducted in an effort to better understand the scope and public perception of corruption, and evaluate the changes in public attitudes toward corruption, the incidence of corruption at the household level, and government progress in implementing reforms that will combat corruption in Mongolia (Sant-Maral, 2017: 10-12).

From observations in this survey and other Sant-Maral Foundation (SMF) surveys (2017), in general, unemployment leads the list of major problems facing the country. If we compare 


\section{Macrothink Institute ${ }^{\mathrm{TM}}$}

this to the situations in March 2017 and March 2016, both unemployment and corruption underwent substantial growth. "Unemployment" increased from 27.8 percent to 34.6 percent, while "Corruption" shifted one position up from forth to third, increasing from 7.7 percent to 9.9 percent.

In March 2017, "Bureaucracy" made an appearance in the top ten most important problems, (it was not among the top ten in 2015 and in 2016). Public perception of "bureaucracy" is closely correlated with corruption.

Factors of corruption could be named as follows (Tamir, 2014: 15):

1. Capacity and structure of civil services

- Undeveloped culture, judgment, values and norms of state and administrative bodies

- Bureaucracy and delayering of public service

- Enclosed state of public organization activities

- Low capacity of management and organization of state bodies

- Overlap, contradiction and ambiguity of laws and regulations

2. Bias of the political system

- Imprudent distribution of legislative, executive and judicial powers

- High level of correlation between politics, executive governance and business field

- Low efficiency of state auditing and internal auditing

- High impact of political parties on the right to vote and to be elected, as well as candidacy

3. Economy

- Low income per person, poor economic development

- Low salary, high living cost

- Improper distribution of income

4. Social and psychological factors

- Public trust in government is weak

- Giving importance to official relations

There is increasing support that bribery is socially unacceptable with 81.8 percent of respondents supporting the statement that "the person who gives a bribe is in the same way responsible as the one who accepts it", which is the also at an all-time high. Political parties, National government, and Parliament remain most corrupt institutions.

The "Absence of will to control corruption from political leadership at a national level" (43.6 percent) and "the habit to solve problems through corrupt practices" (44.1 percent) are considered the main reasons behind corruption.

\section{Independent Authority against Corruption}

The Anti-Corruption Law, adopted on July 8 of 2006, states that the Anti-Corruption Agency will operate to organize corruption prevention and public awareness activities, register, store and inspect declarations of personal interest and income and assets, and conduct intelligence gathering, inquiry, investigation activities to detect corruption crime. The organizational chart and structure was approved by the parliamentary resolution No.03 of January 1, 2007. 


\section{$\Lambda$ Macrothink}

The Anti-Corruption Agency, with centralized management, will operate independently abiding by the principles and in respect of the rule of law, being autonomous and transparent, and confidential as stipulated in article 16.1 of the law on Anti-Corruption.

The Independent Authority Against Corruption implements and overviews the implementation of the Anti-corruption law, Regulation on public and personal interests in public service and prevention of conflict of interest law, Criminal law, Criminal procedure law and conduct its activities in accordance with the Law on budget, Law on sustainable budget, Labor law and other relevant legislation.

The Independent Authority against Corruption is a special, independent government body charged with functions to raise anti-corruption public awareness and education, and corruption prevention activities, and to carry out under-cover operations, inquiries and investigations in detecting corruption crimes, and to review and inspect the assets and income declarations of those required by this law. The mission of this authority is to cooperate with state organizations and citizens to free Mongolian society from corruption and bribery. Not only investigation of criminal offences, but also building public awareness and prevention of corruption are the obligations of IAAC.

\section{Anti-Corruption Actions}

Failure to enforce laws and prosecute persons who commit corruption crimes is a cause for corruption. Creation of atmosphere of zero tolerance of corruption, and the compliance of overall mechanism of government with laws can eliminate all forms of corruption. The poor economic situation in the country is considered to be the cause of corruption, but on the other hand, corruption is a deteriorating phenomenon in economic development.

\subsection{System of Rule of Law}

When tolerance for unethicality is overwhelming, corruption is the most prominent. For example, loss of control over the authority of the public institutions, unclear decision-making, and loss of power of civil society. It is therefore important to establish a systematic management mechanism to prevent public officials from abuse of power (Uyanga, 2014: 16-22). Thus, the rule of law plays an important role in the fight against corruption, regardless of its nature. In the case of a state with rule of law, there is a lack of corruption and already a zero-tolerance environment for corruption. It is therefore crucial to establish a lawful or legitimate government in the fight against corruption.

Participation of law enforcement and civil society organizations is essential to increase the effectiveness of the "rule of law". These include: judicial, police and other law enforcement, investigative agencies, public organizations operating in anticorruption and legal governance, independent auditing and monitoring bodies, mechanisms for oversight of law enforcement, as well as the media in the civil society.

\subsection{Public Engagement and Awareness}

The involvement of the private sector, its staff and every citizen in the fight against corruption will increase the public participation and awareness of anti- corruption and 
encourage the government and its officials to work ethically and fight corruption. In recent years, health, education, land-related organizations, mining, minerals and defense sectors are at risk of high levels of corruption. Therefore, it is necessary to specifically take preventive and enlightenment measures for senior management of state administrative bodies.

To combat and prevent from corruption is the responsibility of everyone. Hence, it is important for the university to implement the curriculum on this issue and for organizations to encourage their employees to be involved in the training of anti-corruption. While the IAAC is conducting trainings of prevention and awareness for public and private organizations, it is important to train national trainers to reach out to every social branch and everybody's attitude towards zero-tolerance for corruption.

It is advisable to take measures step-by-step to establish a consciousness for informing the IAAC of corruption crimes, even if its loss does not affect such person. The fact that the IAAC provides citizens with accurate information is important to free Mongolia from corruption. Thus, there is a need to improve the mechanism of citizen's feedback.

Based on a survey conducted by the Sant-Maral Foundation, if the IAAC starts to receive the personal information about corruption keeping the name and personal information confidential, people will inform of corruption occurrences. This attitude has not almost changed since the start of the survey (2012). This time, more than half of respondents said they would report corruption, if the same condition is satisfied.

\subsection{Law Enforcement, Ethics}

It is important to create conditions for the appointment of candidates for political party affiliation, acquaintances, and friends. For instance, it is necessary to pay attention to the corruption issues related to political party and electoral activities more serious than other political corruption forms, to improve the legal regulation and to end to nominate the party membership.

To eliminate corruption and conflicts of interest in law enforcement and judiciary bodies, first of all it is important to make competence-based appointments to strengthen the capacity of the organization, to increase the transparency of the organization, and to develop monitoring and liability system.

It is also important to pay attention to the lack of respect for public interest, ethics, and accountability of politicians, and to separate political activities from business activities and to end the political party affiliations or connections in the state civil services. To do this, it is advisable for the Public Service to regulate the public and private interests and to improve the regulation of the law on prevention of conflicts of interest, to monitor its implementation and to establish a mechanism for ethical responsibility for politicians.

\section{Conclusion}

The level of corruption in Mongolia's political and law enforcement institutions in 2016 was the same as previous year's figures, indicating that corruption in Mongolia remains widely spread. 
The consequences of corruption in the political arena become the cause of many societal and economic adverse phenomena in the whole country. Experts believe that politicians and state officials spend their money, earned by the corruption, through many ways, including saving at foreign banks, establishing a company in offshore zones, and saving at offshore banks and financial institutions abroad. This is a condition for creating a more organized and hidden form of corruption in the political sphere.

Therefore, we need to pay attention to educate the public and to propagate the view of zero-tolerance for corruption and bribery throughout the society. Experts believe that there is a need for various measures to reduce corruption in the political sphere, especially to establish a system of appointments based on skills, increase transparency in political activities, and increase the willingness of politicians in fighting against corruption. Corruption also destroys the country's economic and social development, and it economically mortifies the public sector and the private sector. On the other hand, corruption is the basis for the crime of human trafficking, money laundering, drug trafficking, and terrorism. Thus, the fight against corruption will have a tangible effect by forming a public view on establishing a society free from corruption and promoting the leadership and participation of civil society and non-governmental organizations in the fight against corruption is not only a duty of the state, but also will and effort of people.

\section{References}

IAAC. (2017). United Nations Convention against Corruption. http://www.iaac. mn/pdf/avligiin_esreg_konvents.pdf.

Independent Authority against Corruption of Mongolia. (2016), Introduction of overall state of corruption and implementation of anti-corruption legislations. Survey Report.

Independent Authority against Corruption of Mongolia (2017). Perception of corruption in political institutions and law enforcement 2016. Survey Report.

Independent Authority against Corruption of Mongolia. (2016), Integrity assessment. Survey Report.

Independent Authority against Corruption of Mongolia (2017). The Implementation of Law of Mongolia on Anti-corruption, and State of Corruption. Ulaanbaatar.

Sant, M. F. (2017). Survey of Perceptions and Knowledge of Corruption. Asia Foundation.

Summers, D. (1995). Longman Dictionary of Contemporary English, Longman: Harlow, UK.

Tamir, N. (2014). Perception, forms and social and economic causes of corruption. Justice Journal, 1(10), 10-15.

Tsevel, Y. (1966). Concise dictionary of Mongolian language. 16.

Uyanga, M. (2014). Policy Level Corruption: Understanding and Global Trend. Ulaanbaatar. 


\section{Copyright Disclaimer}

Copyright for this article is retained by the author(s), with first publication rights granted to the journal.

This is an open-access article distributed under the terms and conditions of the Creative Commons Attribution license (http://creativecommons.org/licenses/by/4.0/). 